\title{
Geografias criativas: afinidades experienciais na relação arte-geografia
}

\section{Creative Geographies: experiential affinities in art-geography relations}

\author{
Carlos Roberto Bernardes de Souza Júnior ${ }^{1}$ (D) \\ Maria Geralda de Almeida ${ }^{2}$
}

\begin{abstract}
Palavras-chave:
Geografia e arte

Percepção

Geopoética

Praticas Inovadoras

Resumo

Caracterizadas por influências reciprocas com práticas artísticas, geografias criativas visam explorar metodologias inovativas no campo da Geografia Cultural. O ensaio objetiva desvelar de que maneiras o (re)torno criativo em Geografia pode potencializar as práticas de pesquisa do geógrafo contemporâneo. Para tanto, foi efetivada pesquisa e revisão bibliográfica, assim como uma aproximação com as provocações filosóficas da fenomenologia existencialista de MerleauPonty. Foi compreendido que os diferentes modos de fazer e escrever Geografia no contexto da virada criativa pode trazer novos alcances para o campo de estudos. Inovações na divulgação dos resultados e no modo de abordar sujeitos/objetos de pesquisa são uma motivação importante para possibilitar o desenvolvimento da ciência geográfica. Conclui-se que as geografias criativas são mais que uma tendência passageira e podem ser uma trilha fundante para inovações na Geografia Cultural contemporânea.
\end{abstract}

Keywords:

Geography and art

Perception

Geopoetics

Innovativepratices

\footnotetext{
${ }^{1}$ Doutorando em Geografia no Instituto de Estudos Socioambientais (IESA) da Universidade Federal de Goiás (UFG), Goiânia, Goiás, Brasil. carlosroberto2094@gmail.com

2 Professora Voluntária do Programa de Pós-Graduação em Geografia do Instituto de Estudos Socioambientais (PPGeo/IESA) da Universidade Federal de Goiás (UFG), Goiânia, Goiás, Brasil. mgdealmeida10@gmail.com
} 


\section{INTRODUÇÃO}

Desenvolvimentos recentes no campo da Geografia Cultural, particularmente nos países anglo-saxões, têm apontado relevante foco na realização de práticas de pesquisa criativas e experimentais (WYLIE, 2010). Isso reverbera em como exploram questões concernentes a temas diversos como percepção espacial, corporeidade, gênero e povos tradicionais (HAWKINS; STRAUGHAN, 2015).

Para abordar tais questões de pesquisa, buscam reatar os elos geográficos com práticas artísticas. De modo similar ao que Geógrafos como La Blache e Humboldt tinham de interface ao romantismo, atualmente os geógrafos realizam conexões com a arte contemporânea (HAWKINS, 2014). Eles buscam inovar ou renovar quando correlacionam metodologias de pesquisa com aproximações performáticas, geopoéticas ou de intervenções/instalações (MAGRANE, 2015).

Destaca-se que essa convergência também é realizada por conta de uma aproximação das artes ao campo de pesquisa geográfico (VOLVEY, 2007). Em movimentos como Land Art ou Environmental Art, os artistas lidam com questões ambientais, cartográficas ou de lugar (CASEY, 2005). A afinidade mútua abrange possibilidades intrigantes para ambas áreas.

O retorno criativo em Geografia está atrelado a essa reciprocidade ativa. Teorizada e idealizada principalmente por Hawkins (2011; 2012; 2014; 2015), a virada pode ser caracterizada pelo seu foco nos entrecruzamentos em que a prática artística surge como objeto ou metodologia de estudo (ESCHUN; MADGE, 2016). Ao pesquisarem realidades geográficas que tangem questões emotivas, experienciais e corporificadas, os geógrafos têm sido profundamente influenciados pelas artes (ROSE, 2016).

Geografias criativas, termo cunhado por Hawkins (2014), visam repensar como o geógrafo se aproxima de determinados problemas de pesquisa. Essa perspectiva compreende tanto uma forma criativa de compreender o espaço geográfico quanto um modo criativo de expor os resultados dos estudos.

Dessa forma, o artigo objetiva desvelar o (re)torno criativo em Geografia e como esse movimento pode potencializar as práticas de pesquisa do geógrafo contemporâneo. Para tanto, realizou-se uma extensa pesquisa e revisão bibliográfica acerca da área, abordando o que é e como se constitui a virada criativa em Geografia e buscando decifrar como essas práticas podem colaborar metodologicamente para a Geografia Cultural. De modo a promover discussão sobre a temática da relação ArteGeografia, a bibliografia concernente foi correlacionada com as provocações filosóficas da fenomenologia existencialista de Merleau-Ponty (1960; 2011; 2012; 2013).

\section{(RE)TORNO CRIATIVO EM GEOGRAFIA}

Metodologias que visam conectar práticas ativas, como pesquisa-ação ou geoetnografia, são recorrentes no campo da Geografia Cultural desde o final do século XX (ALMEIDA, 2013). Contudo, na primeira década dos anos 2000 questões concernentes a sexualidade, gênero, performance, instalações e outras expressões artísticas progressivamente foram introduzidas como tópicos de pesquisa relevantes nessa ciência (MAGRANE, 2015).

Especialmente nos países anglo-saxões (WYLIE, 2010), tais problemas de estudo geraram inquietações que resultaram na necessidade de elaborar novas práticas de pesquisa. As metodologias que se desenvolveram nesse campo intentam responder a essa provocação gerada pelas temáticas contemporâneas que interessaram aos pesquisadores.

Para Hawkins (2014, p.1, tradução dos autores), "a ideia de geografias criativas perpassa, de modo mais amplo, um largo campo de diferentes abordagens e formas de criatividade". A proposta é explorar possibilidades multi e transdisciplinares no campo de estudos geográficos. Como a autora pondera, as diferentes formas de criatividade são utilizadas como inspirações para abordagens variadas de múltiplos objetos de pesquisa.

Hawkins (2015, p.248, tradução dos autores) salienta que "entre as principais justificativas para um (re)torno criativo na geografia, está o potencial das práticas criativas como resposta para a contínua orientação dessa disciplina em direção a metodologias corporificadas e centradas em práticas”.. Ou seja, essa virada é um desenvolvimento gradual que reage às tendências de pesquisas que vêm sendo realizadas pelos geógrafos culturais (ALMEIDA, 2013; HAWKINS, 2014; 2015; CRESSWELL, 2012; ROSE, 2016).

As aproximações com os campos criativos situam-se no sentido de inspirar-se neles para realizar metodologias e no estudo de Geografia e Arte. Como a geógrafa explica: 
O recente (re)torno criativo em Geografia tem visto pesquisadores em vários campos da disciplina adotando métodos geográficos criativos - incluindo artes visuais, produção de imagem, escrita criativa, técnicas performativas - tanto como meio pelo qual a pesquisa é realizada, quanto como maneira de a comunicar e apresentar. (HAWKINGS, 2015, p.248, tradução dos autores)

Em síntese, ela indica uma ampla possibilidade de práticas experimentais centradas em modos criativos de pensar e fazer geografia. Eshun e Madge (2016, p.6, tradução dos autores) salientam que "o (re)torno criativo em geografia tem o potencial de animar a geografia cultural, a expandindo rumo a uma perspectiva pluriversal a que vários mundos são pertencentes". Ao expandir as práticas da Geografia Cultural, a virada criativa pode potencializar uma visão multifacetada sobre diversos temas de interesse a esse campo de estudos.

Além disso, como situa Wylie (2010, p.212, tradução dos autores), objetiva colocar "a geografia cultural mais claramente no campo das disciplinas de artes e humanidades. Acredito que existem muitas possibilidades para trabalhos inter- e multi-disciplinares em colaboração com essas áreas.”. Parcerias com outras disciplinas que visam objetos de estudos similares propiciam abordagens com potencial de centralizar dimensões (inter)subjetivas e emocionais.

Nesse contexto, aproximações com práticas artísticas contemporâneas possibilitam modos de decifrar espacialidades sensíveis do cotidiano. Tuan (1995, p.221, tradução dos autores) ressalta que "a arte nos persuade a observar o efêmero e o insignificante - os eventos, coisas e pessoas que passam por nós enquanto seguimos objetivos que parecem ser dotados de uma permanência e estão sempre próximos em nossos campos perceptivos". As artes, como aponta o autor, evocam relações socioespaciais que estão subjacentes a sua substancialização.

Para Marandola Jr. (2010, p.22) "nas manifestações artísticas estão inscritas geografias da mesma forma que foram necessárias geografias para concebê-las”. Implícita na maneira em que é cristalizada no mundo, a geograficidade da arte destaca perspectivas sensíveis da espacialidade humana. Desse modo, o (re)torno criativo em Geografia potencializa a compreensão dos microcosmos que permeiam a experiência geográfica.
Segundo Hawkins e Straughan (2015, p.213, tradução dos autores), "a exploração de práticas artísticas se tornou um meio para buscar considerações de texturas superficiais conforme essas são sentidas, assim como um campo para pensar as transformações ambientais em suas microescalas". Ao imergir em obras de arte, os geógrafos conseguem identificar relações e percepções ambientais. Particularmente em movimentos como Environmental Art ou Land Art, as instalações se integram em determinadas paisagens e são latentes em geografias a serem estudadas (CASEY, 2005).

Mais que o lugar em que a obra se encontra, há entrecruzamentos geográficos em sua produção e re-significações. Volvey problematiza que "O objeto de arte não apenas se encontra em um lugar (ou uma localidade), ele é um lugar e está particularmente articulado com o lugar, ele é um objeto-lugar" (VOLVEY, 2007, p.10, tradução dos autores). Isso implica destacar que a própria obra gera um lugar reflexivo por meio do contato com os sujeitos que interagem com ela.

No sentido em que "o produto artístico que articula aspectos da espacialidade humana está fadado a articular não apenas uma, mas várias características e dimensões concernentes ao espaço ou lugar" (RICHARDSON, 2015b, p.232, tradução dos autores), há um fecundo campo a ser explorado pelos estudos arte-geográficos. $\mathrm{Na}$ proposta das geografias criativas, a fertilidade de características espaciais inerentes nas obras potencializa o desvelamento de realidades geográficas expostas pelo olhar do artista.

Instalações como Narcisus Garden, de Yaoi Kusama, e Folly (2005-2009), de Waleska Soares, apresentam questões espaciais que somente fazem sentido na medida em que o espectador nelas imergem. Ao andar na obra, as perspectivas se modificam e a percepção é levada a problematizar-se acerca da relação corpo-espacial na qual está engajada.

Como destaca Merleau-Ponty, o que é único na arte "é que ela contém, melhor do que ideias, matrizes de ideias" (MERLEAU-PONTY, 2012, p.157). O filósofo discorre que a obra oferece uma presença ativa à percepção por meio da qual há uma existência sublimada (MERLEAU-PONTY, 2012). Essa característica indica que ela é uma composição a ser compreendida em devir.

É fundante reconhecer que esse modo de ser relacional da arte possibilita uma compreensão que transcenda a compreensões positivistas ou lineares acerca do espaço. Volvey contribui para essa discussão ao apontar que é importante que "a arte seja reconhecida não somente como metodologia científica, mas também como um 
horizonte de conhecimento espacial" (VOLVEY, 2014, p.3, tradução dos autores) Nas geografias criativas, é entendido que "obras de arte podem nos ofertar ricos modos de desestabilizar a subjetividade Cartesiana, com seus objetos e sujeitos separáveis, em favor de um modo mais intersubjetivo e relacional de compreensão das obras e mundos da arte" (HAWKINS, 2011, p.473, tradução dos autores), Diferentes mundos podem ser evocados pelo potencial relacional inerente nessa abordagem.

Em transcendência à percepção objetiva, existem geografias que permeiam experiências atmosféricas, circunstanciais ou afetivas que de difícil explicitação por metodologias formais tradicionais (MCCORMACK, 2015). Para Lorimer (2006, p.516, tradução dos autores), "geógrafos culturais têm sido estimulados a escapar de visões perspectivalistas que fechem seus trabalhos em uma lógica representacional formal e limitante, desse modo, buscarem modos de invocar as mais variadas formas de vida". Como propõe o autor, a atenção recente aos fenômenos decorrentes da espacialidade de entes mais-que-humanos exige um olhar diferenciado por parte da Geografia Cultural (LORIMER, 2014).

Essas temáticas procuram evidenciar os diferentes entrelaçamentos nas experiências dos seres humanos com seu meio. Se objetiva dimensionar questões corpo-espaciais que estão relacionados a intangibilidades. Por salientarem a tenuidade das fronteiras entre "construído" e "natural", a intenção é criar modos de decifrar a complexidade dessas relações espaciais em suas diversas escalas.

Ao propor uma maneira de aglutinar paisagem com narrativa popular, o Scapelore de Bauch (2015) aporta uma metodologia inovadora. Alinhado a prática criativa, a metodologia desvela convergências entre percepções e mundos no contexto de paisagens. Como aponta o autor: "geógrafos e outros estudiosos devem adotar práticas artísticas de produção - de fabricação - para aprofundarem suas próprias agendas de descrever paisagens" (BAUCH, 2015, p.2, tradução dos autores).

Práticas nesse sentido fortalecem a construção de uma perspectiva singular de realizar estudos multidisciplinares alinhados com modos de fazer artístico-científicos. Como Hawkins sumariza:

$\mathrm{O}$ resultado tem sido o desenvolvimento de uma estrutura analítica tripartite para geografias criativas, uma estrutura analítica que sugere que devemos perguntar as seguintes questões interrelacionadas: Qual a 'obra' que a arte realiza no mundo? Quais são as geografias da produção e consumo da obra de arte? E, terceiramente, como nós nos encontramos com as obras de arte? (HAWKINS, 2014, p.237, tradução dos autores)

$\mathrm{O}$ primeiro questionamento da proposta tripartite da autora visa identificar de que maneiras a obra de arte atua no mundo. Isso significa tentar desvelar como uma determinada produção artística efetiva suas espacialidades. Seja por meio da criação de um lugar na Land Art, como estudaram Volvey (2007) e Brady (2015), ou bio-estratigrafias de arte que trata sobre deficiências, como em Macpherson (2015).

Entender as geografias da produção e consumo da arte, ou seja, sua recepção e elaboração, conecta-se intensamente com o sentido espaço-perceptivo da relação sujeitoobra. Implica em questionar: de que maneira a obra é experienciada? Como o artista projeta um significado que se espacializa no mundo? Para desvelar essas condições, estudos como o de Biemann (2011) sobre a produção de videoarte como abordagem de uma contra-geografia do Deserto do Saara e seus povos ou o de Modlin et al (2018) acerca da ausência-presença da memória da escravidão nos lugares-museus de Plantations no sul dos Estados Unidos da América, recorrem a diferentes abordagens para situar criativamente nexos espaciais.

$\mathrm{Na}$ proposição de Hawkins (2014), a última questão diz respeito ao modo como os geógrafos efetuam encontros com as obras de arte. De que maneiras elas interprenetram o olhar geográfico? $\mathrm{Na}$ reciprocidade arte-geografia isso significa explorar a tenuidade dos limites disciplinares e compreender como a prática artística e geográfica podem contribuir uma com a outra.

Se a experiência com a arte afeta a corporeidade de quem a pesquisa, ela também o provoca acerca de como (des)escreve-la. Como discorre Hawkins (2012, p.63, tradução dos autores), têm sido recorrentes "registros expandidos de escritas geográficas que fazem uso de recursos 'crítico-criativos' ou 'geopoéticos' para melhor responder à experiência e campos teóricos estudados".. Em transcendência a estudar essas temáticas, elas devem transformar o modo como os geógrafos descrevem realidades geográficas.

Lévy apontava para tal tendência no final do século XX ao sugerir que : "se compreende que a geopoética não fala de outra coisa que não das pedras, da areia e das flores, do gelo, do sol e das ruinas, ela fala, portanto, dos reencontros do homem consigo mesmo" (LÉVY, 1992, p.34, tradução dos autores). A inquietação de como se 
encontrar com a arte implica em elaborar maneiras geográficas e poéticas que consigam abordar os aspectos existenciais do espaço.

Inerente a esse processo está o desenvolvimento da capacidade adaptativa de desvelamento das espacialidades do invisível e do intangível. Segundo Bauch (2015, p.3, tradução dos autores) "a prática artística deve encontrar a geografia cultural, se sua ontologia relacional for sobreviver às manifestações espaciais". Um dos caminhos para esse encontro é a escrita ou prática geopoética.

O núcleo relacional que aborda o autor (BAUCH, 2015) explicita a necessidade de encontrar maneiras de fazer elementos intersubjetivos emergirem nos trabalhos. Para Magrane (2015), geopoéticas são convites para experimentações estéticas que exprimam novos sentidos aos trabalhos dos geógrafos. Sumariza que "geógrafos que utilizam geografias criativas - nesse caso o uso de poesia - devem se motivar a realizar e aspirar a produzir trabalhos que expandam os limites de ambos campos, geografia e poesia” (MAGRANE, 2015, p.92, tradução dos autores).

Mais que uma chamada à ação para a Geografia Cultural, o (re)torno criativo visa maximizar as potencialidades textuais latentes nesse campo. Rose (2016) situa que múltiplas narrativas podem somarse no sentido de colaborar em uma escrita que consiga evocar os diversos cosmos de cada lugar. Cabe também ao geógrafo fazer parte das vozes das espacialidades que procura interpretar.

Para pesquisar o sentido mais-que-humano, animal/vital, de lugar de renas e sua relação com o pastoreio, Lorimer (2006) recorreu a metáforas e poéticas em um texto que situa-se nas fronteiras da escrita acadêmica tradicional. Também em Homeland (LORIMER, 2014), as geografias da casa de uma família e as diferentes perspectivas memoriais dela são reveladas por meio de uma narrativa próxima ao gênero textual conto.

Couper (2017) retratou a espacialidade do encontro sujeito-natureza recorrendo a sua própria experiência de uma viagem de barco. Pela corporeidade do contado efetivado, a escrita geopoética da autora compõe um relato que coloca noções científicas da geografia em contato com a sensibilidade estética. Os processos imersivos expostos no texto desafiam a noções binárias de separação entre o humano e seu meio.

Cresswell (2017) argumenta que lugares estão inerentemente associados a elementos que dificilmente são reduzidos a escala do objetivo. Objetos, sentidos e práticas são entrecruzados de modo que evocam um outro modo de escrever.
Ao assumir uma postura criativa, o geógrafo (CRESSWELL, 2014) recorre a experimentações na forma de poesia como modo de explicar dinâmicas de lugar em suas pesquisas.

Também é importante destacar o periódico You are Here publicado anualmente desde 1998 pela School of Geography and Development da University of Arizona (YOU ARE HERE, 2018). Ele objetiva explorar o conceito de lugar por meio de práticas experimentais em geografia, como fotografias, poemas, mapas imaginativos e ensaios ou outras expressões criativas.

É perceptível, pelo exposto, que há uma multiplicidade de estudos realizados e em andamento que visam colaborar para uma proposta mais criativa de geografia. Ao utilizar metodologias e abordagens ativas, é possível encaminhar maneiras de compor pesquisas que experimentem corporal e poeticamente com as dinâmicas da realidade geográfica.

Nas geografias criativas, entende-se que os estudos devem ser desenvolvidos processualmente, de modo que sejam abertos para o denso cosmo das experiências. Como Hawkins (2012, p.66, tradução dos autores) realça, "geografias criativas são recorrentemente celebradas por desafiar os espaços, restrições e estruturas da produção de conhecimento geográfico".

O engajamento do pesquisador na identificação das possibilidades é o caminho pelo qual a criatividade direciona a prática ativa. Modos artístico-científicos de pesquisar podem responder a problemas contemporâneos de pesquisa. São, portanto, uma provocação para estender o olhar geográfico para além dos limites disciplinares.

Para Wylie (2010, p.213, tradução dos autores, grifos no original) "geografias culturais criativas podem resultar em uma reforçada habilidade de acessar e abordar públicos de leitura, observação ou escuta mais amplos". Desse modo, o (re)torno criativo pode ser fértil colaboração para a divulgação científica nesse campo de estudos. Ao entrar em espaços que tradicionalmente são das práticas artísticas, a geografia pode dialogar com outros e novos públicos interessados nesse tema.

\section{TRAMAS AFETIVAS - AFINIDADES EXPERIENCIAIS}

A arte é um convite constante para a reflexão. Ela possui uma capacidade expressiva que consegue conectar diferentes matrizes de ideias. A criação artística é uma possibilidade ativa que 
se cristaliza no mundo por meio da vontade de emergência por onde o corpo-sujeito manifesta determinado campo sensorial (DUFOURCQ, 2012). Simultaneamente, a obra de arte é um perpetuo objeto inacabado que se realiza no contato com um sujeito-perceptivo espectador.

Para Richardson (2015a, p.11, tradução dos autores, grifos no original) "nós apreciamos tanto as qualidades plásticas do mundo imaginado quanto as qualidades plásticas da obra em si e, ao menos nos casos em que a obra alcança seus objetivos, nós somos movidos por aquilo que experienciamos". O contato com uma obra artística é uma força movente que mobiliza o centro ativo daquele que a percebe. Como o autor situa, a relação sujeito-arte aflora na condição de uma conexão que gesta um outro mundo (RICHARDSON, 2015b).

Nesse mundo criado relacionamente, ambos entes se interpenetram, obra e pessoa indistinguíveis por aquele instante específico. Se, como propõe Merleau-Ponty (2011, p.105), "olhar um objeto é vir habitá-lo e dali apreender todas as coisas segundo a face que elas voltam para ele", decorre que o ponto de contato é um coabitar entre sujeito e arte.

Ao ser tocado pela obra de arte, o sujeito sensível a completa. Pela sua percepção e imaginação ela passa a ter um outro sentido e um lugar. Ela se espacializa pela consciência ativa que a ela atribui uma cristalização naquele momento. Para Merleau-Ponty (1960, p.83, tradução dos autores):

A obra finalizada não é, logo, aquilo que existe em si como uma coisa, mas aquilo que encontra seu espectador, que o convida a retomar o gesto que a criou e, transcendendo seus intermediários, sem outro guia que um movimento da linha inventada, um traço quase incorporal, lhe faz juntar-se ao mundo silencioso, agora proferido e acessível.

Seja uma pintura, instalação ou performance, a arte é um devir criativo persistente. A obra tem uma vida, diante do espectador, que transcende a intencionalidade original do artista que a concebeu. Como discorre o filósofo (MERLEAU-PONTY, 1960), ela é dotada de lacunas que são significadas pelo circuito ativo da percepção.

$\mathrm{Na}$ perspectiva geográfica isso reverbera na afirmação de Hawkins (2011, p.472, tradução dos autores): "o que se torna claro é a necessidade, como geogógrafos, de explorar a arte não apenas como objeto 'finalizado', mas pensar nas obras de arte como articulações de práticas, artefatos, performances e experiências". Para as geografias criativas, pensar artisticamente significa compreender arte como um processo. A plasticidade metodológica dessa virada está atrelada ao modo como a experiência corporificada atua no mundo.

Dufourcq, em perspectiva merleau-pontiana, discorre que "a profundidade poética se engaja em um jogo incessante acerca da diversidade de pontos de vista" (DUFOURCQ, 2012, p.331, tradução dos autores). É essa capacidade plástica, de múltiplos significados sobrepostos, que faz da poética um potencial latente para o engajamento nos microcosmos dos sentidos da arte.

As expressões poético-criativas tensionam a realidade concebida e mostram fissuras na maneira linear de entender uma determinada coisa. Merleau-Ponty (2013, p.45) pondera que "a arte não é construção, artifício, relação industriosa a um espaço e a um mundo de fora. É realmente o 'grito inarticulado'.". Cada contato perceptivo cria um mundo possível por uma atividade expressiva que é processualmente articulada.

$\mathrm{Na}$ condição de núcleo experiencial, a obra abrange múltiplas potencialidades para cada sujeito que nela imergem. Cada vez que uma pessoa interage com a obra, há algo de novo ou diferente a ser explorado. De acordo com o filósofo,

Um romance, um poema, um quadro, uma peça musical são indivíduos, quer dizer, seres em que não se pode distinguir a expressão do expresso, cujo sentido só é acessível por um contato direto, e que irradiam sua significação sem abandonar seu lugar temporal e espacial. (MERLEAUPONTY, 2011, p.201).

Nessa perspectiva, cada sensibilidade inerente a uma determinada produção artística existe como uma transcendência permanente de seu próprio fenômeno expressivo. Cada obra consubstancia-se como um mundo a ser habitado e decifrado. Não há uma percepção acabada de uma obra, mas perpétuos potenciais relacionais (MERLEAU-PONTY, 2012).

Kaushik (2011, p.9, tradução dos autores) explica que "para Merleau-Ponty, há um sentido em que o objeto artístico é portador de uma expressividade produtora de sentido que contém aspectos espaciais e temporais partícipes de seu próprio mundo". No contexto de geografias criativas, estudos arte-geográficos devem ter a capacidade de desvelar o mundo de cada obra e de gerar mundos por meio de práticas artísticas. 
Esse contato somente é possível porque a obra não é um em-si intangível, mas uma coordenação complexa de fenômenos intangíveis materializados. Como Ramírez (2010, p.57, tradução dos autores) situa, "arte é uma criação de realidade, o que a arte cria é algo real”. Dinamizar uma poiésis geográfica, portanto, perpassa por potencializar o ato de pesquisar como algo que cria um efeito no mundo.

No (re)torno criativo em Geografia, aponta Hawkins (2014, p.11, tradução dos autores), “a arte não, ou não apenas, significa ou representa; ela produz, ela circula no mundo independente de seus criadores, com seus poderes e propriedades singulares". Como no que propõem Merleau-Ponty (2011), Ramírez (2010) e Dufourcq (2012), na arte, o cerne encontra-se na atenção para a poiésis, para aquilo que é criado pela força ativa da arte.

Mais que algo para ser contemplado, "a arte não é nem uma imitação, nem uma fabricação segundo os desejos do instinto ou do bom gosto. É uma operação de expressão" (MERLEAUPONTY, 2013, p.137). Pela externalização criativa que cristaliza no mundo, a arte compõe um modo particular e multifacetado de expor experiências intersubjetivas acerca da espacialidade. Diferentes maneiras por meio das quais sujeitos encontram e realizam seus lugares podem ser dialogadas de modos artístico-geográficos.

Hawkins (2011, p.473, tradução dos autores) ressalta "pensar e escrever sobre assim, assim como fazer arte, pode oferecer um interessante caminho para realizar estudos acerca de nossas experiências de mundo corporificadas". Pensar, escrever e fazer geografia artisticamente é uma oportunidade para decifrar tramas afetivas subjacentes a espacialidade humana. No caso em que se aproximou uma comunidade local por meio de performances aliadas a uma artista, a geógrafa citada anteriormente (2015) conseguiu fazer da pesquisa um modo de fazer-lugar para os habitantes.

Propostas como essas podem ter um impacto efetivo na realidade geográfica de diversos grupos e sujeitos sociais. Para Wylie (2010, p.213, tradução dos autores), a abordagem possibilita "conceptualizar e praticar a geografia cultural como uma performance; como uma escrita criativa, fotografia ou vídeo, obras de arte site-specific, como diferentes formas de cartografar e diagramar". É necessário estar aberto a desenhar, rabiscar, rascunhar, criar croquis e poetizar. Em um trabalho de campo criativo, a experiência deve guiar o olhar pelas tramas afetivas que sensibilizam o pesquisador.

Hawkins (2014, p.188, tradução dos autores) problematiza que 'se 'experienciar' arte nos permite abordar ideias de espaço e a de articulação ou empoderamento corporal no espaço, nós devemos também considerar como o ato de 'fazer' arte pode realizar um trabalho conceitual similar".. A arte pode, mais que expandir, criar outras espacialidades que carregam consigo potencial para encontros criativos com aspectos sensíveis e afetivos da realidade geográfica.

Ao colocar o fazer artístico como uma possibilidade metodológica de pesquisa na Geografia Cultural, é possível que obras geográfico-artísticas sejam parte do trabalho do geógrafo. Esses produtos podem favorecer textos que fazem uso de poemas concretos ou mapas imaginários para explicar determinados fenômenos espaciais. Habilidades artísticas têm muito a contribuir com o modo de condução de pesquisas nessa disciplina.

Narrativas e práticas centradas no corposujeito devem levar em consideração um contato afetivo-ativo com o mundo. $\mathrm{Na}$ inquietação de Marandola Jr. (2016, p.145) por essa via discorre que "o caminho que vislumbro na busca por uma escrita fenomenológica, especialmente no contexto da geografia, é a de um texto que esteja na proximidade com a mundanidade, ou seja, com a própria geograficidade". Ao buscar o ordinário, aquilo que está implícito nas intangibilidades das geografias da vida, é necessário um modo de escrever consiga abarcar essa dimensão.

É necessário trazer ao centro narrativas que se estejam situadas em um campo poéticoliterário que abranja os espaços do hodierno. Para descrever e analisar os lugares da vida, é fundamental que sejam arquitetadas conexões entre metáforas e conceitos. Por meio de imagens poéticas, é possível vislumbrar situações espaciais que retratem laços de afetividade, percepção e corporeidade presentes nas realidades em estudo.

Gratão provoca ao geógrafo alertando que é necessário "um (des)cobrir experiencial e vivencial que (des)vela as 'coisas mesmas' no espaço existencial. Um ato de (a)ventura geográfica que desafia o traçado dos caminhos formais da geografia" (GRATÃO, 2010, p.313). Realizar essa jornada pelas geografias nãoformais da existência por meio de uma proposta criativa exige desconstruir-se e a armar-se de um olhar disposto a experienciar outros mundos.

Lugares de entes mais-que-humanos, como os de que trata Lorimer (2006), somente podem ser experienciados pela imersão em outra forma de ser-no-mundo. Hawkins e Straughan (2015, p.23, tradução dos autores) discorrem que: 
A arte, logo, pode ser apreciada pela sua capacidade de nos engajar com coisas e experiências que transcendem as habilidades do corpo humano de efetivamente sentir ou as experienciar, em síntese, nos ofertando a possibilidade de vislumbrar os mundos humanos e nãohumanos para além de nós mesmos

A abertura proposta pelos autores (LORIMER, 2014; HAWKINS; STRAUGHAN, 2015) demanda um contato corporal que relacione os fenômenos ambientais com o sentido geográfico neles presentes.

Obras de arte que abordam questões concernentes a essa problemática são recorrentes desde o final do século XX (CASEY, 2005) e podem colaborar sobremaneira para a reflexão do geógrafo. Para Casey (2005) entre artistas que têm como inspiração primária um engajamento ativo com a terra, "sua tarefa é a de mover-se com a própria matéria - de se mover nos seus termos, de seguir seus terrenos" (CASEY, 2005, p.98, tradução dos autores). Ao tratarem dos diferentes cosmos dos entrecruzamentos entre humanos e natureza, explicitam caminhos que a Geografia também pode trilhar.

Obras como Ilha Brasílis, de Denise Milan, ou Raios da Manhã (com leito de rio) para São Paulo, de Yoko Ono, ressaltam condições telúrico- ambientais do habitar. Ao substanciarem instalações realizadas com componentes minerais e analogias a natureza, evidenciam tramas de geografias implícitas à unicidade sinérgica sujeito-meio.

Ao abordar questões como mudanças climáticas ou impactos antrópicos em ciclos naturais, artistas têm criado conexões ricas para a discussão geográfica. Aproximar-se de obras que abrangem tais temas pode colaborar para que os geógrafos criem outros modos de sensibilizar o público para reflexões críticas acerca do espaço.

Tais obras convidam o olhar geográfico a se renovar em busca da afetividade pela realidade geográfica. A prática de pesquisa deve deixar-se habitar pelo impulso criativo. Ao ser tocado pela relação perceptiva com a obra de arte, o geógrafo pesquisador pode buscar mais que um sentido representacional-intencional. Por meio da experiência gestada nesse contato, o sujeito perceptivo identifica outros significados subjacentes.

Se, como Merleau-Ponty (2011, p.66) discorre, "a percepção é justamente este ato que cria de um só golpe, com a constelação dos dados, o sentido que os une - que não apenas descobre o sentido que eles têm, mas ainda faz com que tenham um sentido", é a capacidade ativa do corpo-consciência que une-se com o lugar no seio da obra. Limiares se tornam fronteiras tênues entre o espaço do observador e da arte.

$\mathrm{Na}$ perspectiva merleau-pontiana de Kaushik (2011, p.62, tradução dos autores) "a obra de arte, em outras palavras, traz a frente a existência dos sentidos não-temáticos, inexpressivos e implícitos das coisas" Sem dúvida, ao exprimir o que parece não-dizível, a arte contém a capacidade de compor tramas afetivas que são realizadas no contato com os sujeitos. O geógrafo, como sujeito dotado de um corpo sensível, pode imergir nessas obras para compreender tais espaços existenciais. Ao mesmo tempo, ele também pode fazer outras obras emergirem como forma de (d)escrever ou descobrir realidades geográficas das invisibilidades e intangibilidades.

Almeida (2013, p.49) ressalta que "penetrar o invisível, fazer visível o invisível, parecia ser uma habilidade reservada à poesia, à pintura, à escultura etc. A geografia, porém, está demonstrando também ter este dom". As afinidades experienciais com a arte são um fundamento que consegue transformar o trabalho do geógrafo em uma prática criativa. Para desvelar o intangível, há de se consubstanciar modos de fazer e criar que possam tocar tanto aqueles envolvidos na pesquisa quanto quem busca seus resultados.

Segundo Hawkins (2014, p.12, tradução dos autores), "a arte possuí o potencial para transformer o campo em que está trabalhando, de modo a criar possibilidades para diferentes tipos de sujeitos, conhecimentos e mundos". Para pensar uma geografia que consiga empreender estudos sobre o mais-que-humano e a condição existencial do ser-no-mundo na Terra, faz-se fundamental buscar outras vozes geográficas.

É importante alcançar uma maneira de expressar as tramas afetivas e experiência. Uma linguagem mais conectada à narrativa da existência que perpassa pelas condições de vida e da realidade geográfica pode expor as vísceras dos sujeitos-lugares. A arte é um caminho para uma geografia dinâmica que esteja disponível para ser entrecruzada e habitada pelo devir da Terra.

\section{CONSIDERAÇÕES FINAIS}

O (re)torno criativo em Geografia apresenta-se como uma possibilidade fértil para renovação 
dessa disciplina no início do século XXI. Suas abordagens indicam trilhas a serem percorridas por um olhar que busca captar as tramas afetivas que permeiam o mundo vivido. Particularmente na Geografia Cultural, provoca os pesquisadores a reposicionarem suas concepções de como fazer ciência.

Obras de arte contemporânea, principalmente de movimentos como Land Art e Environmental Art, tratam de temas convergentes ao interesse geográfico. As aproximações em ambos campos indicam que existe um núcleo de interesses comuns que pode ser explorado por geógrafos e artistas para promoverem reflexões sobre situações ambientais, lugares e percepções espaciais.

Encontros arte-geográficos possuem reciprocidade na maneira como uma área pode dialogar, influenciar e colaborar com a outra. Metodologias ativas centradas na experiência de fazer ou imersão na arte, contribuem para modos criativos para condução de estudos. Escritas, ilustrações ou performances geopoéticas são maneiras de encontrar outras narrativas que contribuam para decifrar múltiplas realidades geográficas.

Como desafio permanece a busca por uma escrita geopoética que tenha capacidade evocativa para exprimir as experiências espaciais dos sujeitos. Condições de ser-no-mundo e habitar a terra podem ser decifradas e descritas de modo a transcender as fronteiras entre o científico e o artístico. Destarte, os geógrafos colocam-se no centro imersivo de práticas inovativas e dinâmicas.

Para que não seja apenas um modismo que venha a desaparecer nos próximos anos, é necessário que haja um processo de reflexão permanente acerca das Geografias Criativas. As práticas, ainda que expansivas por sua própria natureza, precisam alinhar-se com estudos teóricos que propiciem embasamentos relevantes para as pesquisas.

Geografias Culturais do século XXI têm muito a se beneficiar por abordagens multifacetadas e criativas. Conforme os temas de pesquisa progressivamente desafiam o olhar geográfico rumo a novas práticas, é fundamental provocar seu fazer e sua escritura na busca de caminhos para responder ao mundo contemporâneo.

\section{REFERÊNCIAS}

ALMEIDA, M. G. A propósito do Trato do Invisível, do Intangível e do discurso na Geografia Cultural. Revista da ANPEGE, v.
9, n. $11, \quad$ p. $41-50, \quad 2013$. https://doi.org/10.5418/RA2013.0911.0004

BAUCH, N. A Scapelore manifesto: Creative geographical practice in a Mythless Age. GeoHumanities, v.1, n.1, 2015, p.1-21. https://doi.org/10.1080/2373566X.2015.106971 6

BIEMANN, U. Counter-geographies in the Sahara. In: DEAR, M.; Et. Al. (Orgs.) Geohumanities: Art, history, text at the edge of place. London: Routledge, 2011, p.162-172.

BRADY, E. Aesthetic regard for nature in Environmental and Land Art. In: HAWKINS, H.; STRAUGHAN, E. (Orgs) Geographical Aesthetics: Imagining space, staging encounters. Ashgate: Surrey, 2015, p.197-210.

CASEY, E. Earth-Mapping: artists reshaping landscape. Minneapolis: University of Minnesota Press, 2005.

COUPER, P. R. The embodied spatialities of being in nature: encountering the nature/culture binary in green/blue space. Cultural Geographies, v.25, n.2, p.285-299, 2018. https://doi.org/10.1177/1474474017732978

CRESSWELL, T. Geographies of poetry/poetries of geography. Cultural Geographies, v.21, n.1, p.141-146, 2014. https://doi.org/10.1177/1474474012466117

CRESSWELL, T. Towards Topopoetics: Space, place and the poem. In: JANZ, B. B. (Org.) Place, space and hermeneutics. Cham: Springer, 2017, p.319-332. https://doi.org/10.1007/978-3-319-52214-2_23

DUFOURCQ, A. Merleau-Ponty : Une ontologie de l'imaginaire. New York: Springer, 2012. https://doi.org/10.1007/978-94-007-1975-0

ESHUN, G.; MADGE, C. Poetic world-writing in a pluriversal world: a provocation to the creative (re)turn in geography. Social \& Cultural Geography. V.7, n. 3, p.1-9, 2016.

GRATÃO, L. H. B. Por entre becos \& versos - a poética da cidade vi(vi)da de Cora Coralina. In: MARANDOLA JR, E.; GRATÃO, L. H. B. (Orgs.) Geografia e Literatura: ensaios sobre geograficidade, poética e imaginação. Londrina: EDUEL, 2010, pp.297-328.

HAWKINS, H. Dialogues and Doings: Sketching the Relationships between Geography and Art. Geography compass. V. 5, n.7, p.464-478, 2011.https://doi.org/10.1111/j.17498198.2011. 00429.x

HAWKINS, H. Geography and art. An Expanding field: Site, the body and practice. Progress in human geography. V.37, n. 1, p.52-71, 2012.

https://doi.org/10.1177/0309132512442865

HAWKINS, H. For creative Geographies: Geography, Visual Arts and the Making of 
Worlds. Routledge: London, 2014. https://doi.org/10.1177/1474474014530961

HAWKINS, H. Creative geographic methods: knowing, representing, intervening: on composing place and page. Cultural Geographies, v.22, n.2, p.247-268, 2015. https://doi.org/10.1177/1474474015569995

HAWKINS, H.; STRAUGHAN, E. Geographical Aesthetics: Imagining space, staging encounters. Ashgate: Surrey, 2015. https://doi.org/10.4324/9781315584355

KAUSHIK, R. Art and Institution: Aesthetics in the Late Works of Merleau-Ponty. London: Continuum International Publishing Group, 2011.

LÉVY, B. L'empreinte et le déchiffrement: géopoétique et géographie humaniste. Cahiers de géopoétique, v.1, p.27-35, 1992.

LORIMER, H. Herding memories of humans and animals. Environment and Planning D: Society and space. v. 24, n.1, p.497-518, 2006. https://doi.org/10.1068/d381t

LORIMER, H. Homeland. Cultural Geographies, v.21, n.4, p.583-604, 2014. https://doi.org/10.1177/1474474014547335

MAGRANE, E. Situating Geopoetics. GeoHumanities, v.1, n.1, p.86-102, 2015. https://doi.org/10.1080/2373566X.2015.107167 4

MARANDOLA JR, E. J. Humanismo e arte para uma geografia do conhecimento. Geosul, v. 25, n.49, p.7-26, 2010. https://doi.org/10.5007/21775230.2010v25n49 p7

MARANDOLA JR, E. J. O imperativo estético vocativo na escrita fenomenológica. Revista da Abordagem Gestáltica. v. 22, n.2, p.140147 , https://doi.org/10.18065/RAG.2016v22n2.4

MCCORMACK, D. Devices for doing atmospheric things. In: VANINI, P. (org.) Non-representational methodologies. London: Routledge, 2015, p.89-111.

MCPHERSON, H. Biostratigraphy and Disability Art: An introduction to the Work of Jon Adams. In: HAWKINS, H.; STRAUGHAN, E. (Orgs.) Geographical Aesthetics: Imagining space, staging encounters. Ashgate: Surrey, 2015, p.165-180.

MERLEAU-PONTY, M. Signes. Paris: Gallimard, 1960.

MERLEAU-PONTY, M. Fenomenologia da percepção. São Paulo: Martins Fontes, 2011.

MERLEAU-PONTY, M. A prosa do mundo. São Paulo: Cosac Naify, 2012.

MERLEAU-PONTY, M. O olho e o espírito. São Paulo: Cosac Naify, 2013.

MODLIN, E. A., Et. Al. Can plantation museums do full justice to the story of the enslaved? A discussion of problems, possibilities, and the place of memory. GeoHumanities, v.4, n.2, p.335-359, 2018. https://doi.org/10.1080/2373566X.2018.148672 3

RAMÍREZ, M. T. Creativity. In: SEPP, H. R.; EMBREE, L. (Orgs.) Handbook of phenomenological aesthetics. London: Springer Science+Bussiness Media, 2010, pp.5761.

RICHARDSON, B. The "spatio-cultural dimension": overview and a proposed framework. In: RICHARDSON, B. (Org.) Spatiality and symbolic expression: on the links between Place and Culture. New York: Paulgrave macmillian, 2015a, p.1-20. https://doi.org/10.1057/9781137488510_1

RICHARDSON, B. Symbol, situatedness, and the individuality of literary space. In: RICHARDSON, B. (Org.) Spatiality and symbolic expression: on the links between Place and Culture. New York: Paulgrave macmillian, 2015b, p.21-40. https://doi.org/10.1057/9781137488510_3

ROSE, M. A place for other stories: Authorship and evidence in Experimental Times. GeoHumanities, v. 2, n.1, p.132-148, 2016. https://doi.org/10.1080/2373566X.2016.115703 1

TUAN, Y. Passing strange and wonderful: aesthetics, nature and culture. New York: Island Press, 1995. https://doi.org/10.2307/432053

VOLVEY, A. Land Arts : Les fabriques spatiales de l'art contemporain. Travaux de l'Institut de Géographie de Reims, v.129, n.1, p.3-25, 2007. https://doi.org/10.3406/tigr.2007.1527

VOLVEY, A. Entre l'art et la géographie, une question (d')esthétique. Belgeo, v.3, p.1-25, 2014. https://doi.org/10.4000/belgeo.13258

YOU ARE HERE. Tucson: University of Arizona. 1998-Anual. Eletrônica, disponível em <http://www.youareheregeography.com/>; acesso em 10 de janeiro de 2018.

WYLIE, J. Cultural geographies of the future, or looking rosy and feeling blue. Cultural Geographies. v.17, n.2, p.211-217, 2010. https://doi.org/10.1177/1474474010363852 